اثر استخدام التعلم التعاوني على وفق إستر اتيجية تدريس الأقران

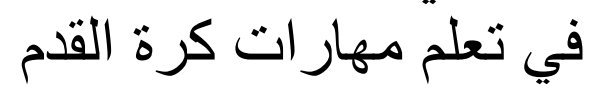

$$
\text { جامعة صلاح الدين / كلية التربية الرياضية اكرم سلية }
$$

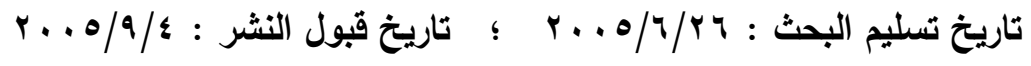

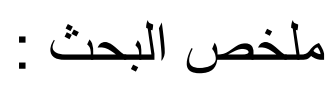

يهدف البحث الى الكثف عن اثر استخدام التعلم التعاوني وفق استراتيجية تعليم الاقران

في تعلم بعض المهارات الاساسية بكرة القدم •

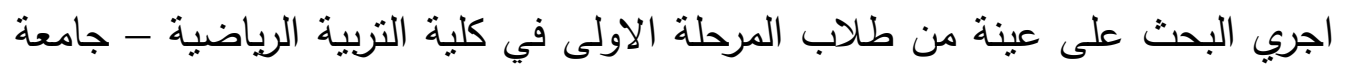

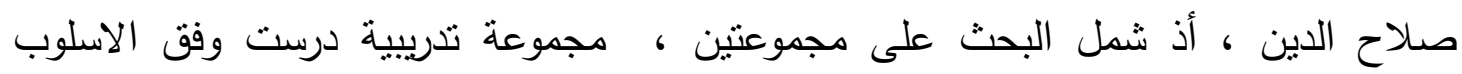

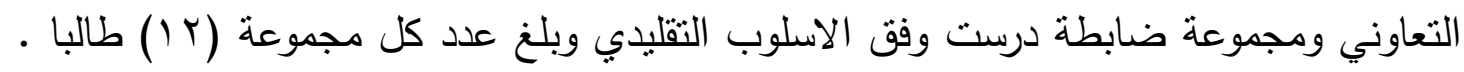
اما اداوت البحث فتمتلت بالاختبارات المهارية (دحرجة - اخماد - سيطرة ) بكرة القدم واجرى

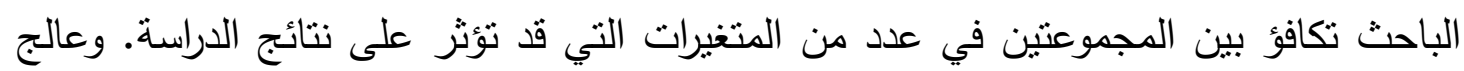

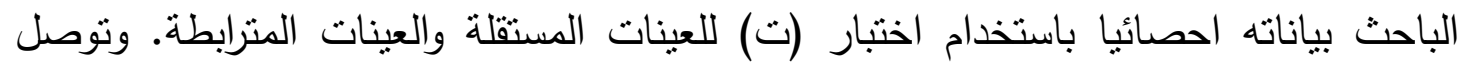

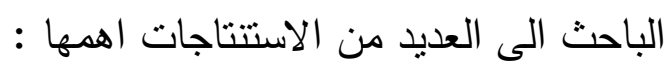

تفوق المجموعة التي درست وفق استراتيجية تدريس الاقران على المجموعة التي درست

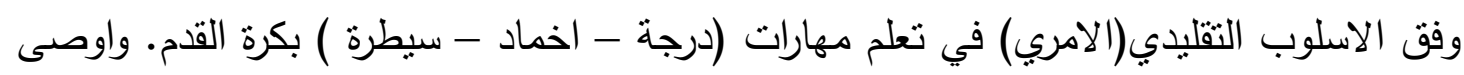

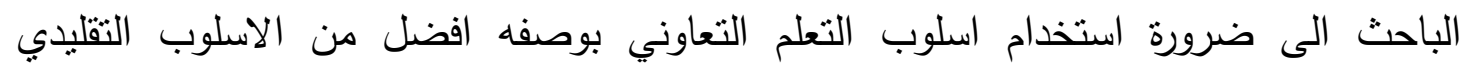
(ألأمري) في تعلم مهارات (درجة - اخماد - سيطرة ) بكرة القدم •

\title{
The Effect of Using Cooperative Learning According to Peer Tutoring in Teaching Some of the Basic Skills in Football
}

\section{Feda Akram Salem}

\section{Abstract:}

\section{University of Slahaldeen - College of Sport Education}

The research aims at getting acquainted with the effect of using cooperative learning according to the teaching strategy of same-age students in teaching some of the basic skills in football. The research was 
conducted on a sample of first-year students in College of Physical Education, University of Sallah Al- Deen. The research included two groups: an experimental group taught by using the cooperative manner and a control group taught by using the traditional one. The number of each group was a (12) student. As for research items, they included

trapping, dribbling and control in football. The researcher conducted equivalence between the two groups in regard to the number of variants that could affect the study results. The researcher treated his data statistically throughout using $\mathrm{T}$ - test for both, the independent samples and correlated ones.

The researcher has reached to a number of conclusions, the most important one is the following: In acquiring skills such as trapping, dribbling and control in football, the experimental group, which was taught by using the cooperative learning manner exceeded the control group, which was taught by using the traditional one.

The researcher recommended that there should be a necessity of using the cooperative learning manner as it was proved to be better than the traditional one in teaching the skills of trapping, dribbling and control.








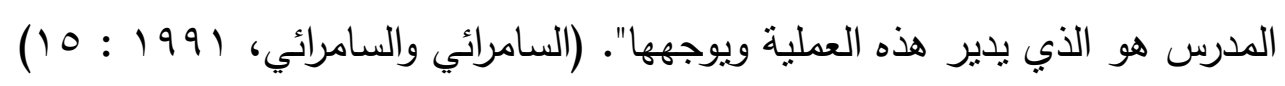

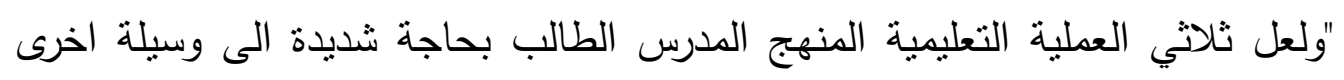

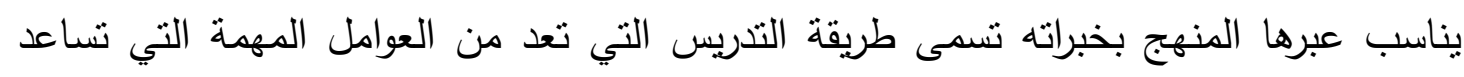

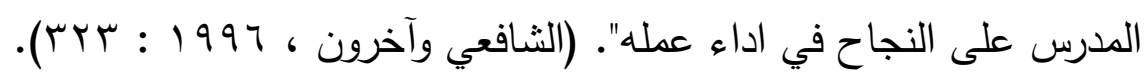



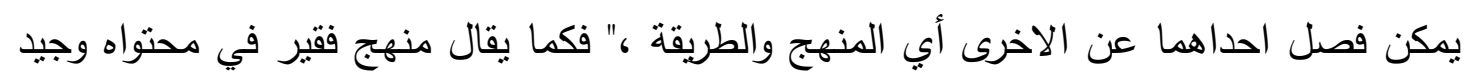

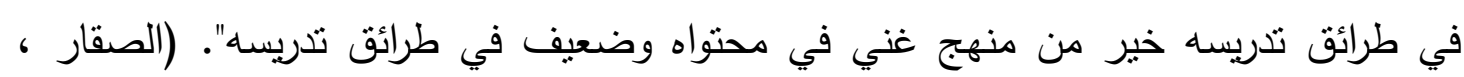
(r) : $191 \mathrm{~V}$

ونتيجة للتغيرات والنطورات السريعة في تكنولوجيا التعليم تراجعت الاساليب والطرائق التقليدية التي كانت معتمدة في التدريس لتحل بدلا منها اساليب وطرائق ترتكز على الاهنمام

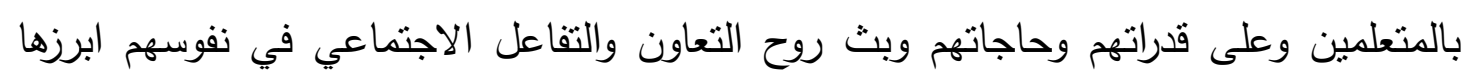

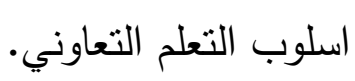

وتعد مادة كرة القدم من بين ميادين المعرفة في كليات واقسام التربية الرياضية التي لا يقتصر اهداف تدريسها على الجانب المعرفي والمهاري فقط بل يتجاوز ذلك الى تتمية المهارات الاجتماعية لدى الطلبة لممارستها منل التعاون والمشاركة والتتظيم وتحمل المسؤولية.

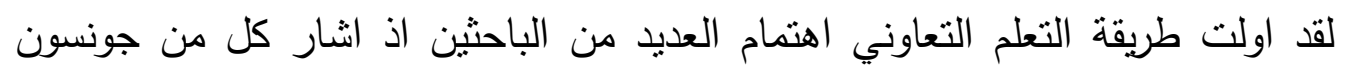

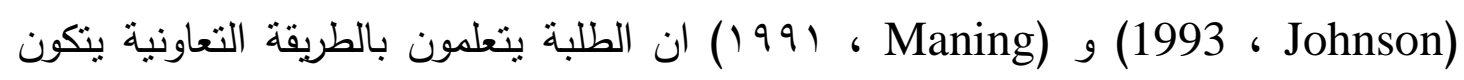

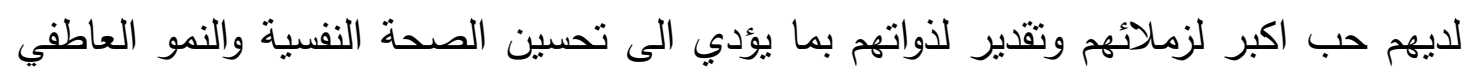

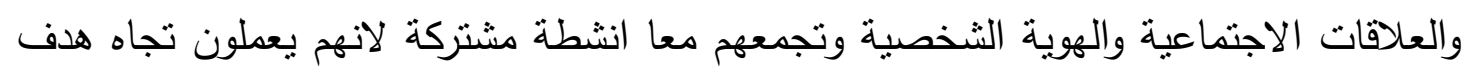

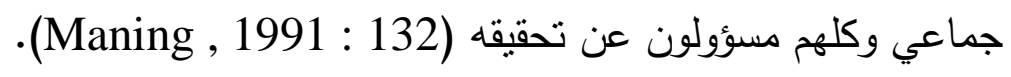
وعلى الرغم من تعدد الاستراتيجيات في التعلم التعاوني فانها تلتقي عند قاسم مشترك

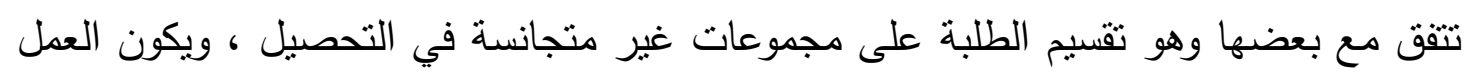
في المجموعة فريقا واحدا ويتعلم الطلبة من بعضهم من دون مساعدة المدرس الا عند الضرورة وجميع هذه الاستراتيجيات تتطلب اهداف جماعية ومسؤولية فردية وانسجاما حتى تؤدي نتائج ايجابية. وتبنى الباحث استراتيجية تدريس الاقران وتتجع هذه الاستراتيجية الاعتماد المتبادل

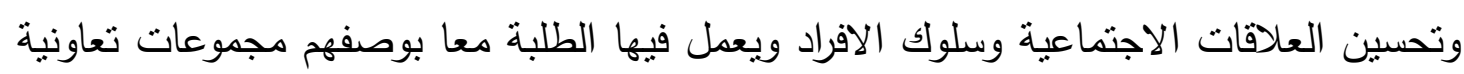
تؤدي الى مهمات تعليمية ذات اهداف مشتركة. وفي ضوء ما تقدم برزت الهية البحث فيما يأني 
1. اعداد برنامج تعليمي باستخدام احدى استراتيجيات التعلم التعاوني (تدريس الاقران) في تعلم



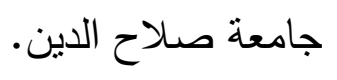

r. تحديد مهمات تعليمية لكل فرد من افراد المجموعه التعاونية يكون مسؤولاً عن تعليمها لأفراد مجموعته التعاونية فضلاً على الاعتماد المتبادل فيما بينهم.



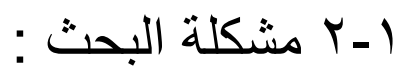

على الرغم من تعدد الاساليب الحديثة في العطلية التعليمية الا انه لازال التنريس مقتصرا

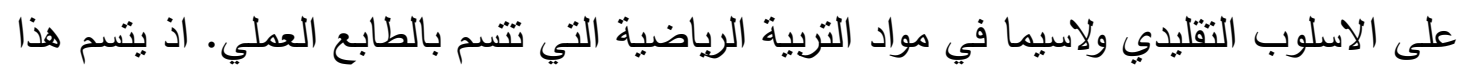
الاسلوب بالسيطرة الواضحة للمدرس على مجريات التدريس بشكل كبير مما يعكس الجانب

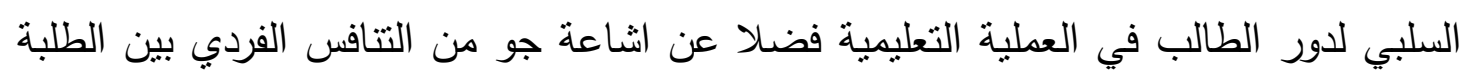
وهذا ما يؤثر سلبا في الترابط الاجتماعي والتعاون بين الطلبة ومن ثم قد ينعكس على شخدية لطنية الطالب مستقبلا.

كما اثنارت الادبيات الى ان هنالك اهتماما متزايدا بطرائق التدريس واستراتيجياتها

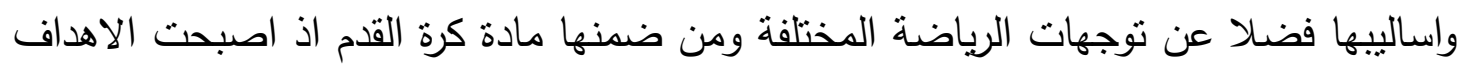



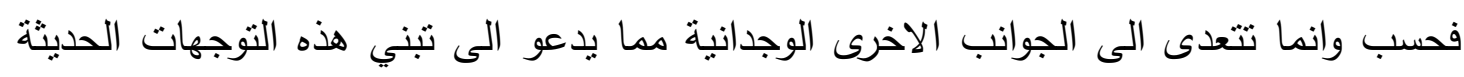

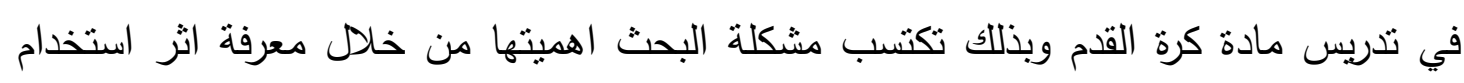
التعلم التعاوني على وفق استراتيجية (تدريس الاقران) في تعلم بعض المهارات الاساسية بكرة القدم مقارنة بالتعلم التقليدي(الامري) ؟ وفي التئي

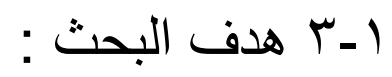
الكثف عن اثر استخدام التعلم التعاوني على وفق استراتيجية (تدريس الاقران) في تعلم مهارات كرة القدم · مهن

\section{1 - أ فرضية البحث:}

توجد فروق ذات دلالة احصائية بين منوسط درجات المجموعة التجريبية التي تدرس

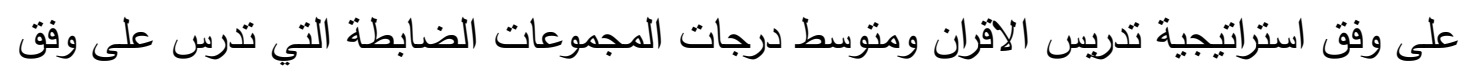
الأسلوب التقلبدي(الامري) في بعض المهارات الاساسية بكرة القدم. 


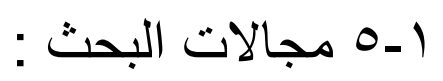

ا. المجال البشري : طلاب السنة الدراسية الاولى في كلية التربية الرياضية - جامعة صلاح الدين.

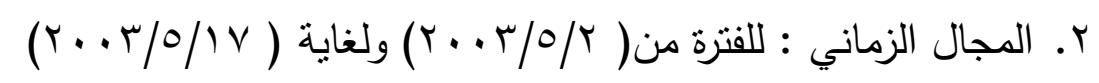

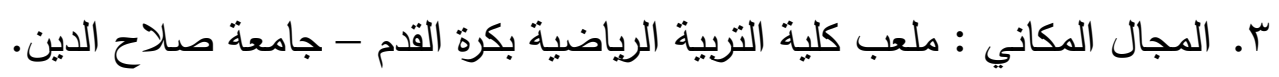

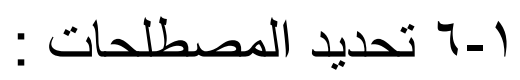

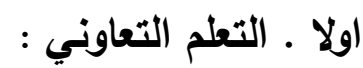

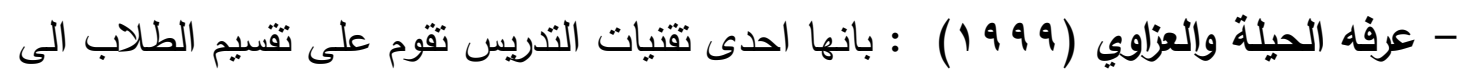
مجموعات صغيرة تعمل معاً من اجل تحقيق هدف او اهداف تعلمه الصفي. (الحيلة

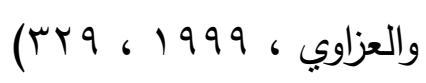

- وعرفه الحريري : بانه الاسلوب المتبع من قبل معلم الفصل في استخدام طريقة المجموعات

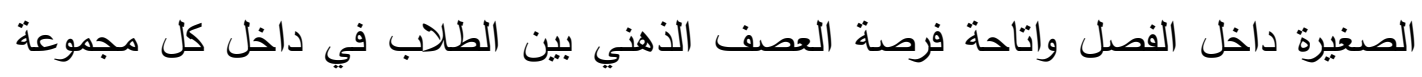



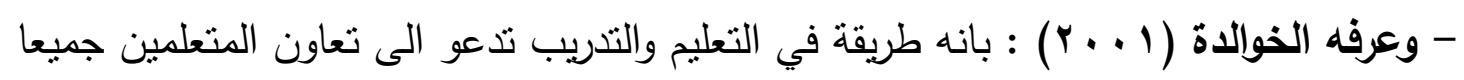



ثانيا. استراتيجية تدريس الاقران:

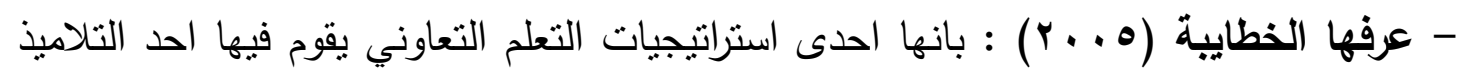
بالتدريس لاقرانه داخل المجموعة ، حيث تقسم مهام التعلم التي تتضمن مهارات بين الافراد

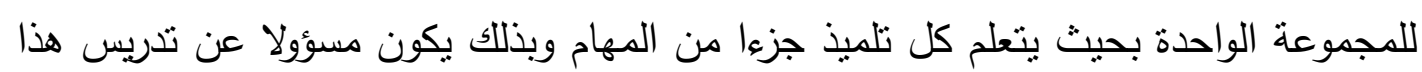



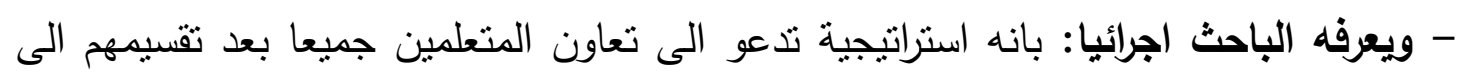

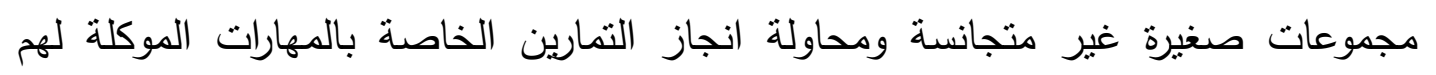
(الاخماد - السيطرة - الدحرجة) والتي يحددها مدرس المادة بشكل تعاوني. 


$$
\begin{aligned}
& \text { Y - الدر اسات النظرية و الدر اسات المشابهة }
\end{aligned}
$$

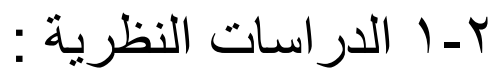

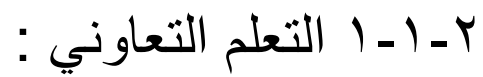

يعد التعلم التعاوني شكلا من انكال التفاعل الاجتماعي الذي يجعل الطلاب افرادا

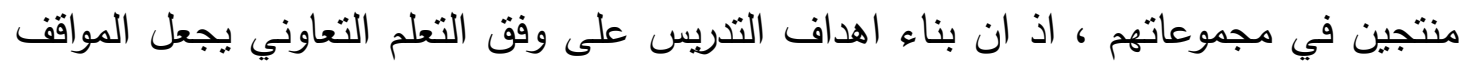

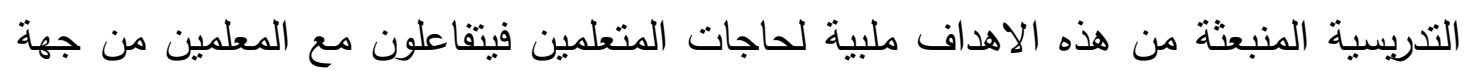

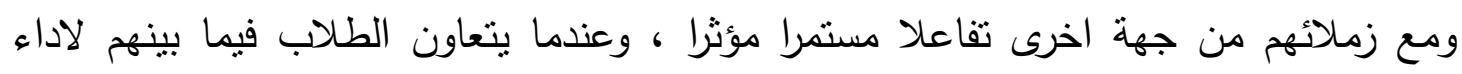
المهمات التعليمية بدلا من التتافس فان هذا يقلل من الثعور بالعداء بين الطلاب ويخلق اتجاهات تعاونية ايجابية لايهم.

ان طبيعة التعلم التعاوني تقترض انه لكي يحقق الطلاب اعظم فوائد ممكنة في تحصيلهم

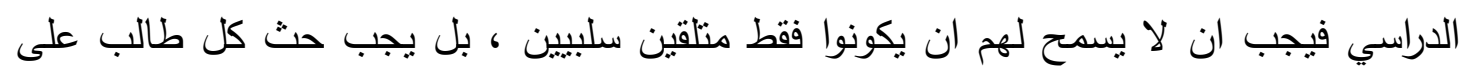



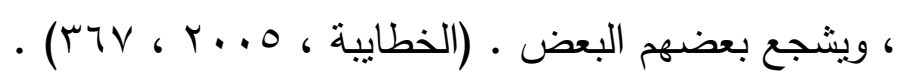

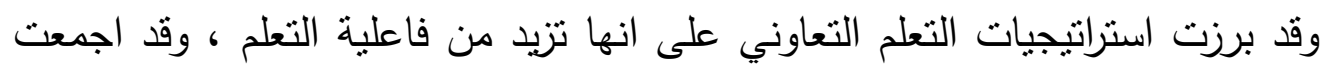

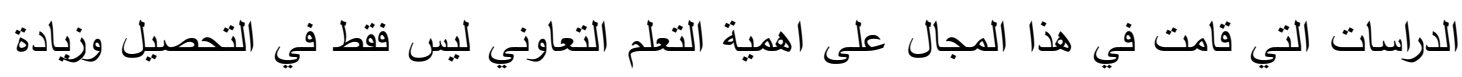



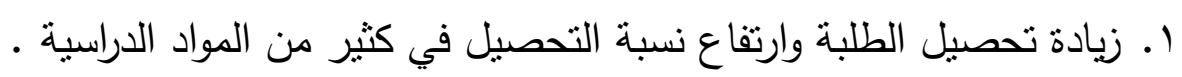

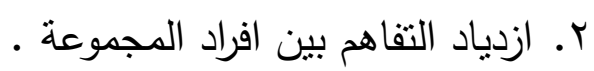

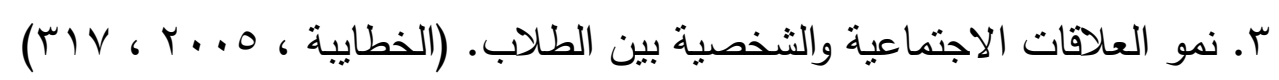



توجد استراتيجيات متعددة للتعلم التعاوني وهناك من يذكرها استراتيجيات والراي الآخر

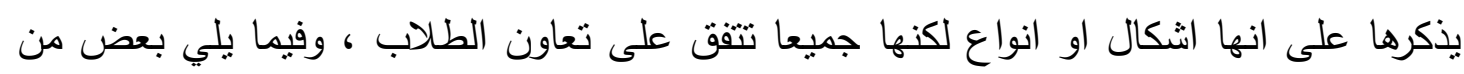
هذه الاساليب : ا ـ الائر التعلم (التعلم التعاوني الجمعي)

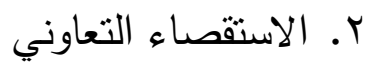

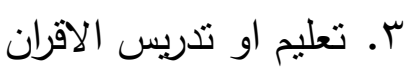

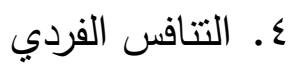



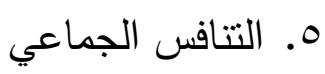

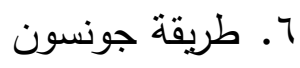
V. طريقة المشروع جرن 


$$
\begin{aligned}
& \text { 1. طريقة جكسو (1) }
\end{aligned}
$$



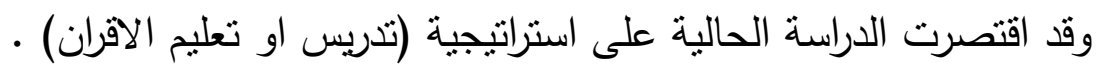

$$
\text { r - ا - ب تدريس او تعليم الاقران : }
$$

وفيه يقوم احد التلاميذ بالتدريس لاقرانه داخل المجموعة ، حيث تقسم المهام التي

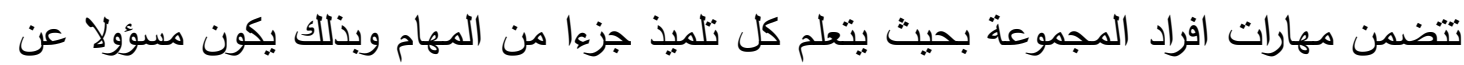
تدريس هذ الجزء لبقية المجموعة وبذللك يتعاون جميع افراد هذه المجموعة في فهم هذا الجزء فيما

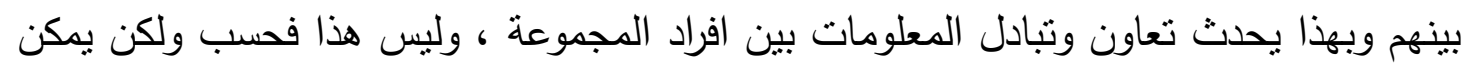

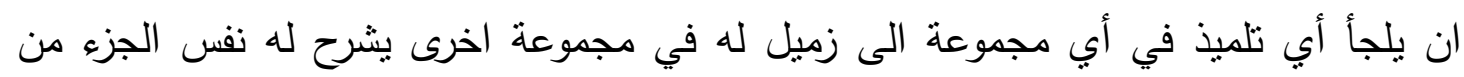

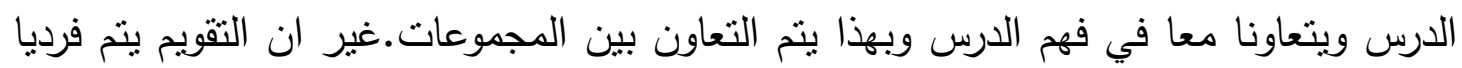
حيث يقوم كل فرد على حدى في ضوء تحصيله للدرس ككل.

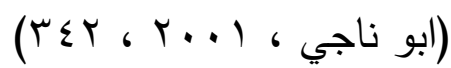

\section{الفرق بين التعلم التعاوني والتعلم التقليدي :}

ا ـ في التعلم التعاوني تبنى الاستراتيجيات التعاونية على التآزر بين الاعضاء ذلك التَآزر الناتج عن الاهداف المخطط لها جيدا ، في حين لا يتوفر بين الطلبة في التعلم التقليدي.

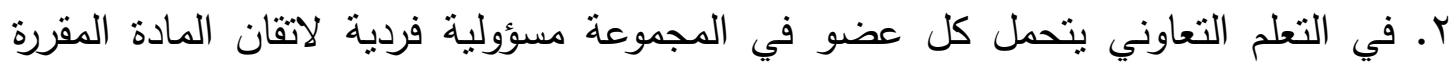
للتعلم ، اما في التعلم التقلبدي فلا توجد مسؤولية محددة لكل متعلم عن ناتج التعلم.


في حين لا يتوفر ذللك في التعليم التقليدي •

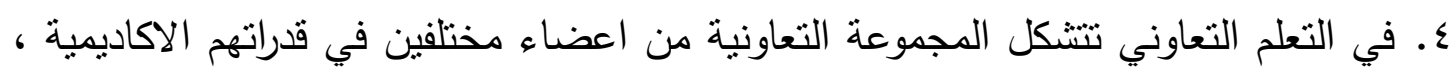

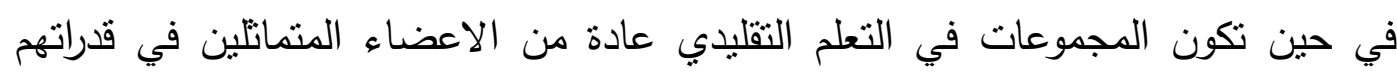

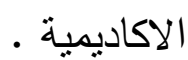

ه. في التعلم التعاوني تسعى الاهداف المخطط لها الى تحقيق علاقات طيبة بين اعضاء المجموعة وكذلك توفر الدرجة القصوى من التعلم في حين يهنم الاعضاء باهنهاء العمل


(ro) : 1999

7. في التعلم التعاوني ينظم المدرس الاجراءات التي تناعد اعضاء المجموعة على تحليل درجة فاعليتها في التعلم التعاوني ، في حين لا ينم ذلك في التعلم التعاوني .

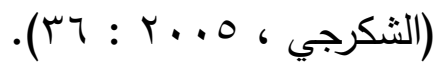




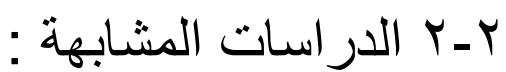



"اثث التطم التعاوني في تحقيق الاهداف التطيمية لفعالية التس الارضي"


لمستويات (المعرفة الفهم التطبيق) والاهداف النفس-حركية (العناصر البدنية والدهارات الحركية)

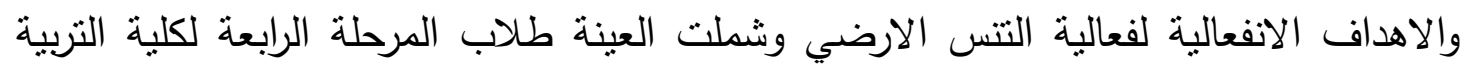



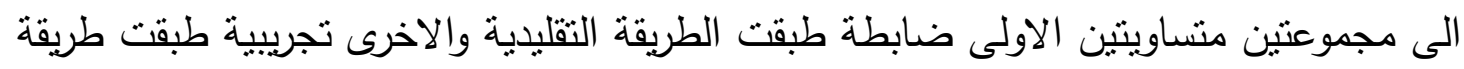
التعلم التعاوني. وتم قياس مستوى تحصيل الطلبة بوساطة اختبار التحصيل المعرفي واختبارات التاني

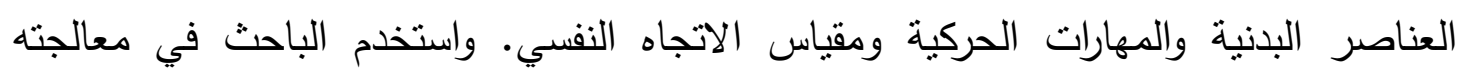



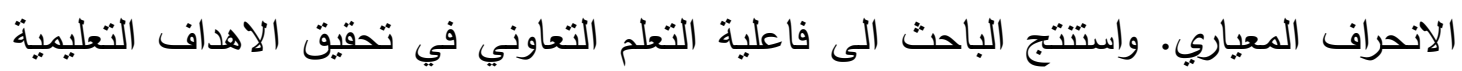
لفعالية التنس الارضي · (الاطوي ، 1991)



"اثثر استخام اسلوب التطلم التعاوني على وفق الاختبارات البينية في تطلم بعض المهارات

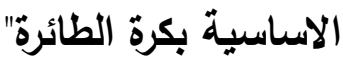

هدفت الدراسة الى الكثف عن اثر اسليب التعلم النعاوني على وفق الاختبارات البينية

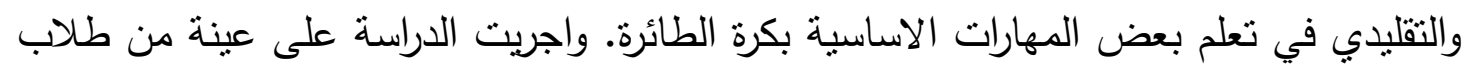

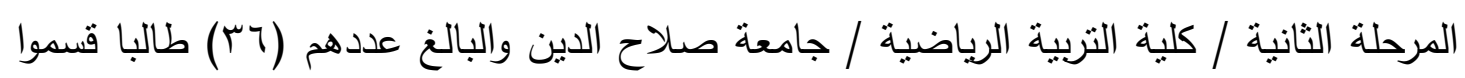



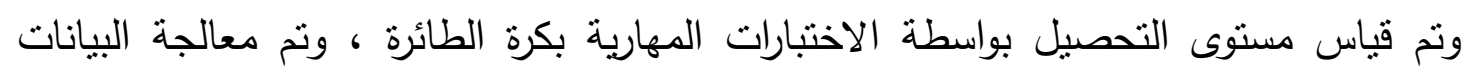

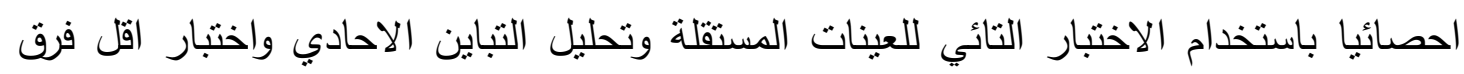

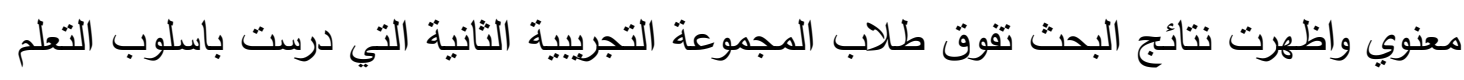

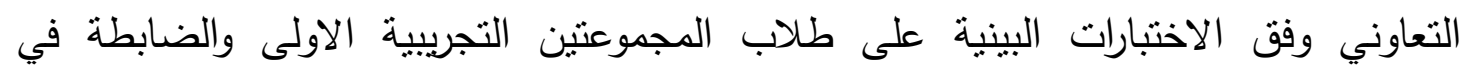

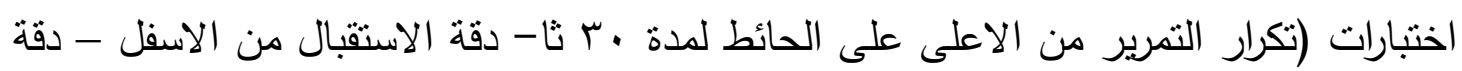

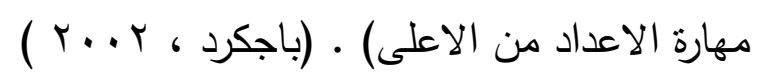




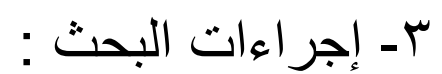

"- ا منهج البحث : استخدم الباحث المنهج التجريبي لملاعته طبيعة البحث.



تمتل مجتمع البحث من طلاب السنة الدراسية الاولى في كلية التربية الرياضية - جامعة

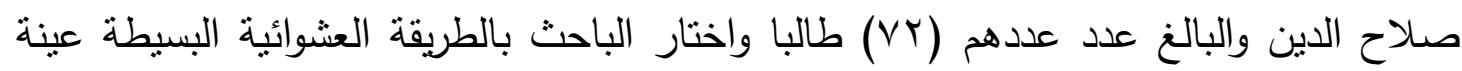
البحث ، اذ متلت شعبة (B) المجموعة التجريبية الاولى وشعبة (C) المجموعة الضابطة. والبالغ عددهم (r ( ) طالب لكل مجموعة.

r- " تحديد المتغير ات وضبطها : تم تحديد متغيرات البحث اذ متل التعلم التعاوني وفق تدريس الاقران المتغير المستقل، في حين مثلت المهارات الاساسية المحددة بكرة القدم (دحرجة - اخماد - سيطرة) المتغيرات

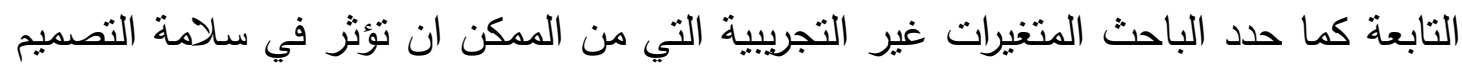

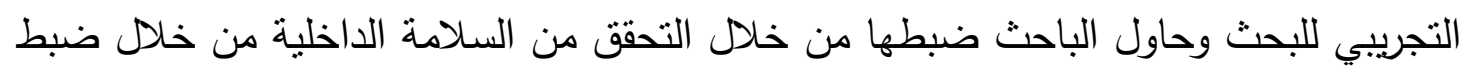
(ظروف التجربة والمتغيرات المتعلقة بالنضج وادوات القياس وفروق الاختبار في افراد العينة والتاركون في التجربة). كما تحقق الباحث من السلامة الخارجية من خلال ضبط العوامل الآتية (تأثير التعدد في المتغيرات المستقلة واثز الاختبار القبلي وانز اجراء التجربة من خلال السيطرة على المادة الدراسية والمدرس وتوزيع الحصص).

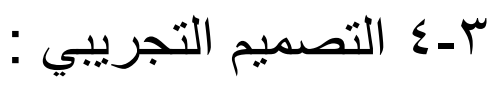

تمنل التصميم التجريبي بالتصميم الأتي( تصميم المجموعات المتكافئة ذات الاختبارين القبلي و البعدي) وتكون التصميم من مجموعتين( مجموعه تجريبية درست على وفق استراتيجية تدريس الاقران،ومجموعة ضابطة درست على وفق الأسلوب التقليدي(الامري)).

$$
\text { بـ } 0 \text { نكافؤ مجمو عتي البحث : }
$$

قام الباحث باجراء التكافؤ في عدد من المتنغيرات التي يعتقد انها تؤثر في نتائج البحث

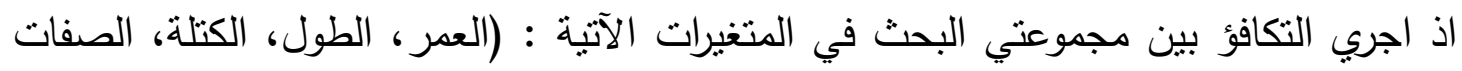


اجري التكافؤ في الصفات البدنية التي تلعب دور مؤثز في تعلم المهارات الاساسية



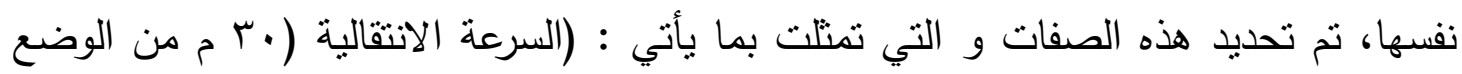

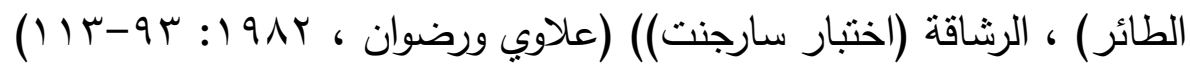



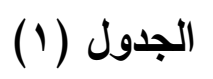

يبين التكافؤ بين المجموعتين التجريبية والضابطة في المتغيرات المحددة

\begin{tabular}{|c|c|c|c|c|c|}
\hline \multirow{2}{*}{ المحتسبة } & \multicolumn{2}{|c|}{ المجموعة الضابطة } & \multicolumn{2}{|c|}{ المجموعة التجريبية } & \multirow{2}{*}{ المتغيرات } \\
\hline & $\varepsilon \pm$ & س & $\varepsilon \pm$ & س & \\
\hline$\cdot, 9 V$ & $10,0 \leqslant$ & $r \leqslant 0, \cdot \wedge$ & $1 \cdot, 01$ & Yo.,01 & العمر / بالاثهر \\
\hline$\cdot, V \varepsilon$ & $\varepsilon, \wedge)$ & $|V \varepsilon, \varepsilon|$ & 0,74 & $1 \vee 7, \cdot 1$ & الطول / سم \\
\hline $1, T V$ & $\varepsilon, \varepsilon r$ & $7 \cdot, \Sigma)$ & $1 \cdot, 74$ & $77, Y_{0}$ & الكتلة / كغم \\
\hline $1, \varepsilon r$ & $\cdot$, YO & $\varepsilon, \cdot 1$ & דז, • & r,Ar & السرعة الانتقالية • بّم /ثا \\
\hline $1, \cdot \varepsilon$ & $\cdot, \leqslant 1$ & $1 r, .0$ & • & $1 r, q r$ & الرشاقة /ثا \\
\hline$\cdot, \leqslant 7$ & $r, \cdot \Lambda$ & $r r, \cdot \Lambda$ & צr, r r & rT, Tr & الدحرجة / ثا \\
\hline$\cdot, \mathrm{VT}$ & $r, \cdot r$ & $0, Y_{1}$ & $1, v$ & 0,1 & الاخماد / درجة \\
\hline דוצ' & 7,9 & $1 \leqslant, 0$ & $\varepsilon, \wedge$ & $11, r$ & السبطرة / عدد \\
\hline
\end{tabular}

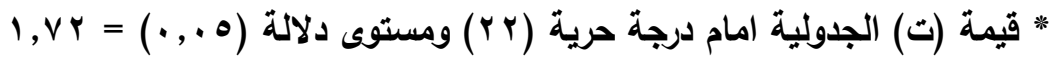

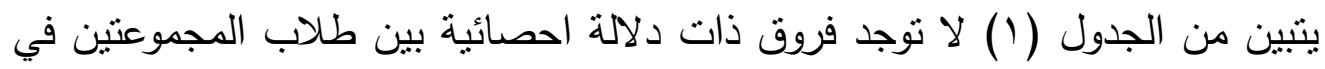
المتغيرات المحددة مما يشير الى تكافؤ المجموعتين في هذه المتغيرات.

ب-7 و وسائل جمع البيانات استعان الباحث وسائل البحث الآتية البانية - الاختبارات البدنية: السرعة الانتقالية ( • بام من الوضع الطائر)، الرشاقة ( اختبار سارجنت).

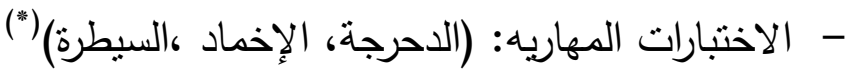



(") ان الاختبارات البدنية والمهارية المستخدمة في البحث هي اختبارات مقننة تتمتع بمعاملات صدق و ثثات و

موضوعية وحسب المصادر العلمية في فعالية كرة القدم ـ فضلا عن ذلك تم استخدامها في دراسات و

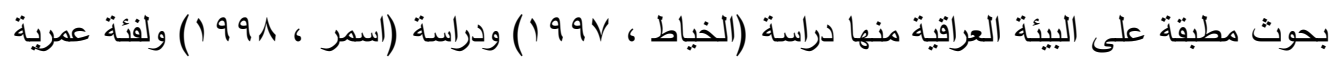

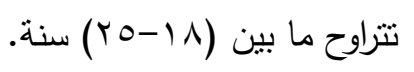


تضمن البرنامج التعليمي (Y Y) وحدة تعليمية موزعة على مجموعتين وبواقع (T) وحدات



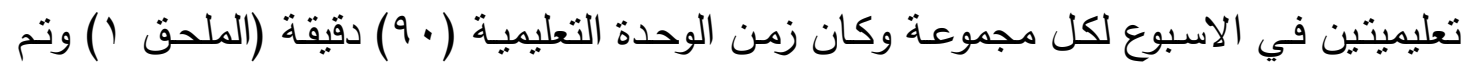
عرض البرنامج على مجموعة من الخبراء من ذوي الاختصاص (") في مجال كرة القدم وابداء

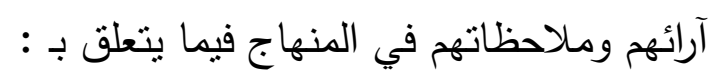

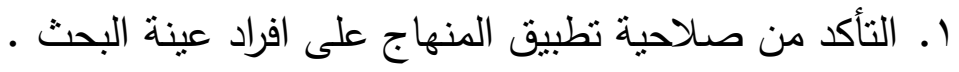

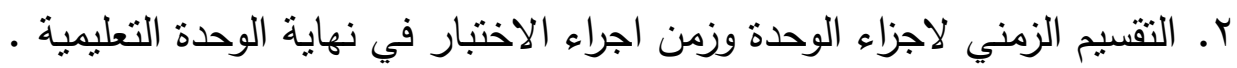
r. التمرينات التي وضعت من اجل تحقيق هدف المنهاج .

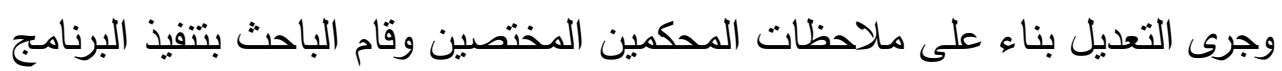

ب-1 التجربة الاستطلاعية لأسلوب التدريس :





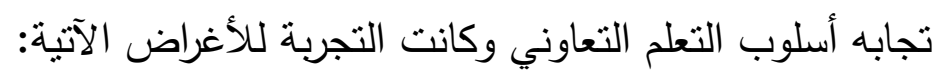
1. التأكد من سيطرة مدرس المادة لاخراج درسه بالأسلوبين (تدريس الاقران - التقليدي) r r التأكد من الوقت المستغرق في تتفيذ التمارين. r. علاحية وكفاية الملعب والادوات المستخدمة في البحث.

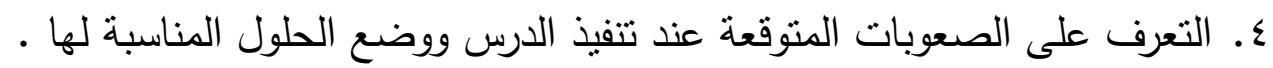

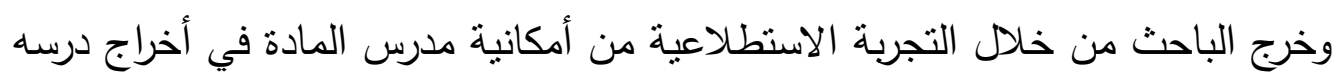


الاستراتيجية و تلافي المعوقات التي قد تلاقيه.

\section{ب-9 تطبيق التجربة النهائية :}

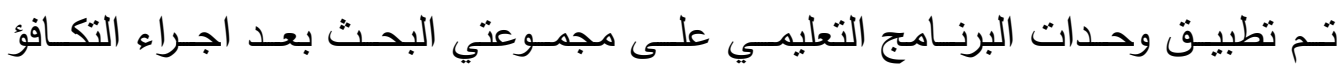
بينهم(الاختبار القبلي) في عدد من المتغيرات التي تم ذكرها آنفا وتم تطبيق وحدات البرنامج التعليمي على مجموعتي البحث وكالآتي :

كلية التربية الرياضية / جامعة الموصل كلية التربية الرياضية / جامعة الموصل / جامعه الموصله

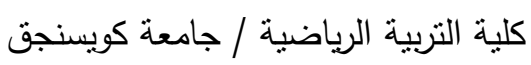

$$
\begin{aligned}
& \text { (*) - أ. م. د ضرغام جاسم محمد } \\
& \text { - أ. م. د م. د فكي محمود جاسم } \\
& \text { - م. - محري خوشناو }
\end{aligned}
$$


- تم التدريس باستراتيجية (تدريس الاقران اذ قسم طلاب المجموعة الى مجاميع صغيرة عددها

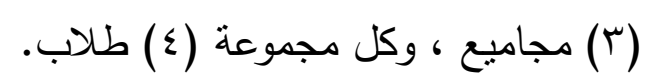

يقوم مدرس المادة بعرض الهدف التعليمي لللدس وشرح المهارة فضلا عن تقديم نموذج جيد

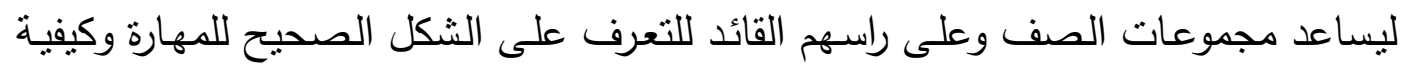



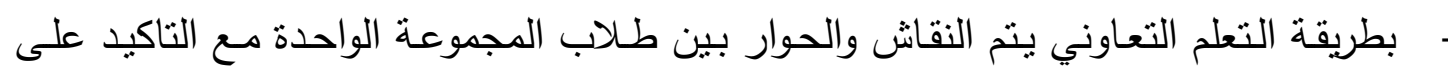
العمل بهدوء ونظام مع ابراز دور القائد. في الجزء التطبيقي من الوحدة التعليمية تقوم المجاميع التعاونية بالانتقال الى اماكنهم لغرض الترات تتفيذ المهمات التعليمية. - ـ يتم الاثراف على تتفيذ المهمات الجزئية من قائد المجموعة ويكون الانتقال من مهمة جزئية

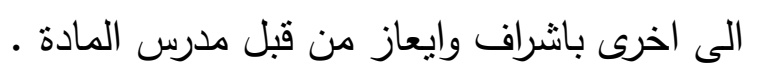


ويبدي المساعدة للمجموعة عند حاجاتهم اليه عن طريق قائد المجموعة.

\section{- المجموعة الضابطة:}

تم تدريس المجموعة الضابطة بالاسلوب (التقليدي المتبع) وكالآتي :

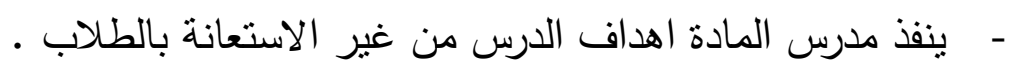




- - ينمو في هذا الاسلوب عملية التتافس الفردي في تتفيذ المهارة . - يكون المدرس مسؤولا عن المراقبة وتصحيح الاخطاء فرديا.

$$
\text { ب- • ا الاختبار ات البعدية: }
$$

تم اجراء الاختبارات البعدية بعد الانتهاء من تتفيذ البرنامج التعليمي وقد اتبع الباحث

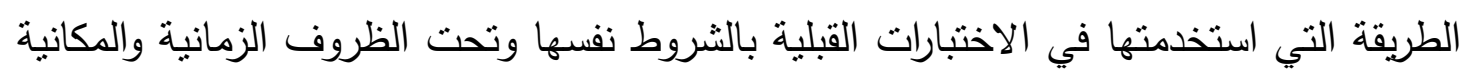
وادوات الاختبار نفسها . 




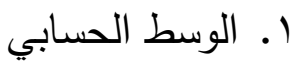

r. - ب. الانحراف المعياري

r. اختبار (ت) للعينات المستقلة منساوية العدد.

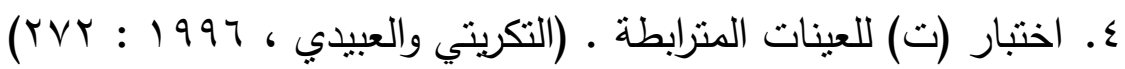

ع - عرض و وناقشة النتائج:

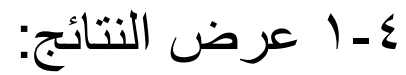

ـ ـ ـ ـ ا عرض الفروق بين الاختبار القبلي و البعدي للمجمو عة التجريبية:



يبين دلالة الفروق بين الاختبارين القبلي والبعدي للمجموعة التجريبية

\begin{tabular}{|c|c|c|c|c|c|}
\hline \multirow{2}{*}{ ت المحتسبة } & \multicolumn{2}{|c|}{ الاختبار البعدي } & \multicolumn{2}{|c|}{ الاختبار القبلي } & \multirow{2}{*}{ المتغيرات } \\
\hline & $\varepsilon \pm$ & س س & $\varepsilon^{ \pm}$ & س س & \\
\hline $1,7 \pi$ & $\cdot, V$ & $r 1, \cdot r$ & T, T & & دحرجة/ ثا \\
\hline$\uparrow, \wedge \wedge$ & $\cdot, 90$ & $\wedge, 1$ & $1, V$ & $0, \wedge$ & اخماد/درجة \\
\hline 11,1 & $7, r$ & $r O, V Y$ & $\varepsilon, \wedge$ & $11, r$ & سيطرة/عدد \\
\hline
\end{tabular}



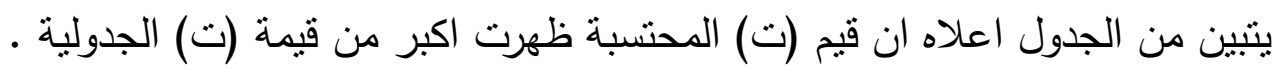

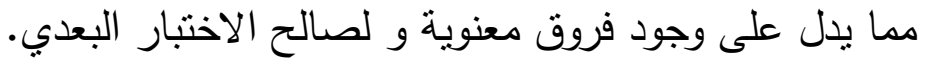



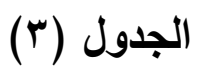

يبين دلالة الفروق بين الاختبارين القبلي والبعدي للمجموعة الضابطة

\begin{tabular}{|c|c|c|c|c|c|}
\hline \multirow{2}{*}{ ت المحتسبة } & \multicolumn{2}{|c|}{ الاختبار البعدي } & \multicolumn{2}{|c|}{ الاختبار القبلي } & \multirow[t]{2}{*}{ المتغيرات } \\
\hline & $\varepsilon \pm$ & س س س & $\varepsilon^{ \pm}$ & س س & \\
\hline $0, \cdot r$ & $\cdot, \wedge r$ & $r, .0$ & $r, \cdot \lambda$ & rr, & دحرجة/ثا \\
\hline 0,19 & $1, \varepsilon$ & $v, \ldots$ & $r, \cdot r$ & $0, r_{1}$ & اخماد/درجة \\
\hline$r, v r$ & 0,1 & $19, \varepsilon$ & 7,9 & $1 \leqslant, 0$ & سيطرة/عدد \\
\hline
\end{tabular}



يتبين من الجدول اعلاه ان قيم (ت) المحتسبة ظهرت اكبر من قيمة (ت) الجدولية .

وهذا يدل على وجود فروق معنوية و لصالح الاختبارات البعدية.

rv 
ـ ـ ــ عرض الفروق في الاختبار البعدي بين المجموعتين الضابطة و التجريبية



يبين دلالة الفروق في الاختبار البعدي بين افراد المجموعتين

\begin{tabular}{|c|c|c|c|c|c|}
\hline \multirow{2}{*}{ ت المحتسبة } & \multicolumn{2}{|c|}{ المجموعة الضابطة } & \multicolumn{2}{|c|}{ المجموعة التجريبية } & \multirow{2}{*}{ المتغيرات } \\
\hline & $\varepsilon \pm$ & س & $\varepsilon \pm$ & س & \\
\hline$r, r$ & $\cdot, \wedge r$ & $r r_{0} .0$ & $\cdot, \vee \vee T$ & $r 1, \cdot r$ & دحرجة/ثا \\
\hline$r, 10$ & $1, \varepsilon$ & $v, \cdot$ & $\cdot, 90$ & $\wedge, 1$ & اخماد /درجة \\
\hline$r, \varepsilon \varepsilon$ & 0,1 & $19, \varepsilon$ & $7, r$ & ro, VY & سيطرة/عدد \\
\hline
\end{tabular}

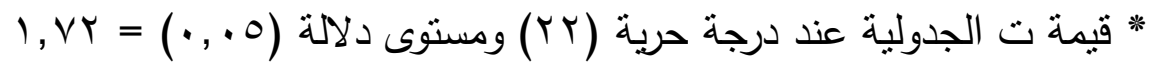

يتبين من الجدول اعلاه ان قيم (ت) المحتسبة ظهرت اكبر من قيمة (ت) الجدولية . وهذا يدل على وجود فروق ذات دلالة معنوية بين افراد المجموعتين وبمراجعة الاوساط الحسابية يتضح ان هذا الفرق هو لصالح المجموعة التجريبية التي درست على وفق استراتيجية تدريس الاقران • وهذه النتيجة تدل على قبول فرضية البحث البديلة ورفض الفرضية الصفرية.

يتضح من الجدولين (r r r) الى وجود فروق ذات دلالة معنوية في نتائج اختبارات

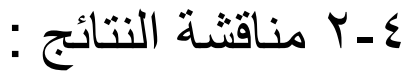

المهارات الحركية القبلية والبعدية ولصالح الاختبارات البعدية للمجموعتين التجريبية والضابطة. ويعزى اسباب الفروق المعنوية لاى مجموعتي البحث الى تاثير البرنامج التعليمي فقد لاحظنا تقدما عند افراد مجموعتي البحث في الاختبارات البعدية ولكن بنسب متفاوتة ـ اذ يثير (علاوي) ان لطرق واساليب التدريس اهمية بالغة في العملية التعليمية وان هذه الطرائق والاساليب

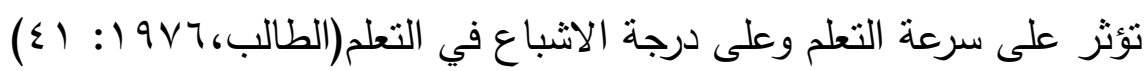
كما اظهرت النتائج وجود فروق ذات دلالة معنوية في تعلم المهارات الحركية (دحرجة - اخماد - سيطرة) بين مجموعتي البحث و لصالح المجموعة التجريبية ويعزي الباحث سبب ذلك الى الآلية التي تميزت بها سنراتيجية التعلم التعاوني (تعليم الاقران) ومزايا هذا النمط من التعلم المتمنتة بالتعاون بين افراد المجموعة الواحدة وما اتاحته هذه الاستراتيجية من فرص ايجابية للطلبة للتفاعل فيما بينهم والاعتماد المتبادل بين المتعلمين فضلا عن اتباع اسلوب التعلم التعاوني يؤدي الى زيادة الاهتمام بتتظيم المادة التعليمية تتظيما جيدا من حيث التسلسل وحسب الخطة الدرس المعدة لذلك. 
وربما تعزى هذه النتيجة ايضا الى اثر الاقران و تعزيزهم لبعضهم البعض لان التتعمين

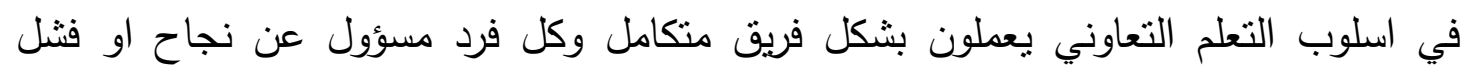



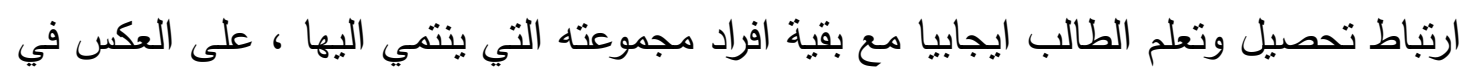

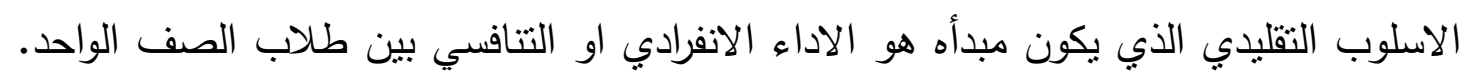

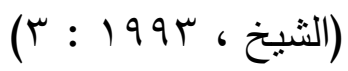

كما ان استخدام التعلم التعاوني يعمل على المشاركة الفعالة بين الطلاب ويبدي تعاونا

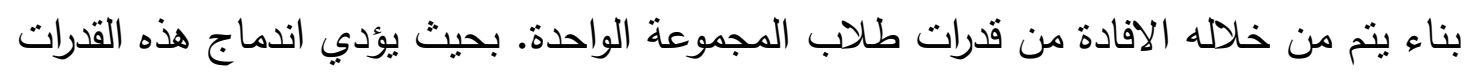

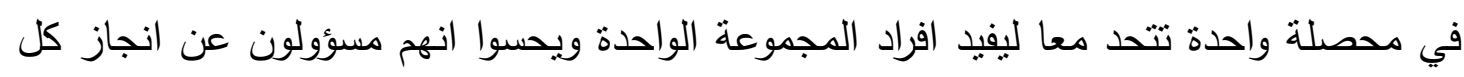
فرد في تحقيق عمل جماعي فيقبلوا على التعلم بحماس وفاعلية اكثر من التعلم بالاسلوب التهاب

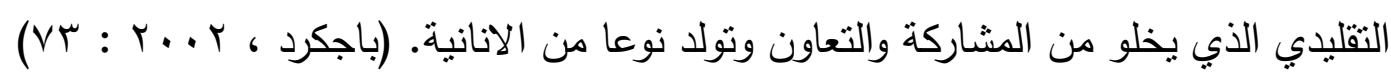

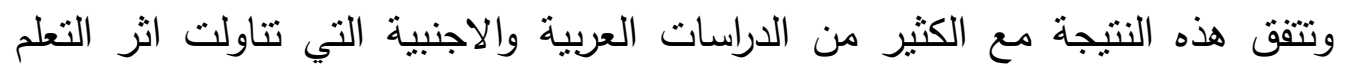

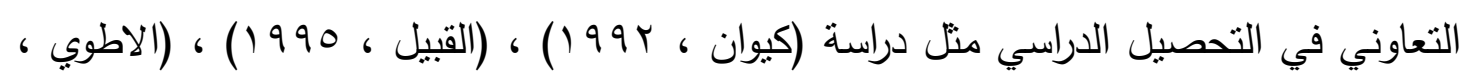

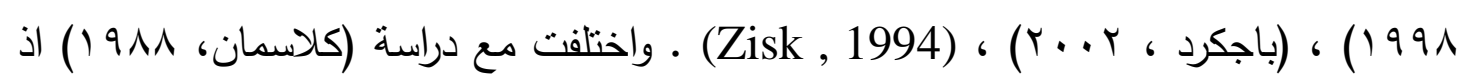
لم يبرهن التعلم التعاوني على أي اثر في زيادة تحصيل الطلبة قياسا بالطريقة التقليدية. (ابراهيم ، 1999)

هـ الاستنتاجات و التوصيات و المقترحات: 0 - 1 الاستنتاجات:

من خلال نتائج البحث استتنج الباحث مات يأتي : ا ـ أثر استراتيجية تدريس الاقران في تعليم المهارات الاساسية (دحرجة - اخماد - سيطرة) بكرة

$$
\text { القدم ايجابيا. }
$$

r. أثر الاسلوب التقليدي(الامري) في تعليم المهارات الاساسية المحددة بكرة القدم ايجابيا.


الذين تعلموا على وفق الاسلوب التقليدي في المهارت الاساسية (دحرجة - اخماد - سبطرة) بكرة القدم.

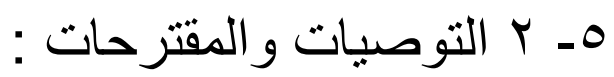

1. التأكيد على استخدام اسلوب التعلم التعاوني بوصفه افضل من الاسلوب التقليدي في تعليم مهارات (دحرجة - اخماد - سبطرة) لكرة القدم. 
r. اجراء بحوث مماثلة تثبت امكانية استخدام التعلم التعاوني باستراتيجياته المتعددة في مراحل دراسية اخرى وفق مواد دراسية اخرى .

\section{المصادر العربية والاجنبية :}


تحصيل المعرفة والاحتفاظ بها لدى طلبة العلوم الاجتماعية ، مجلة مركز البحوث التربوية ،

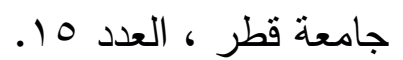
r. الاطوي ، وليد وعد اله .(1991). اثر التعلم التعاوني في تحقيق الاهداف التعليمية لفعالية التتس الارضي، اطروحة دكتوراه غير منشورة، كلية التربية الرياضية ، جامعة الموصل.

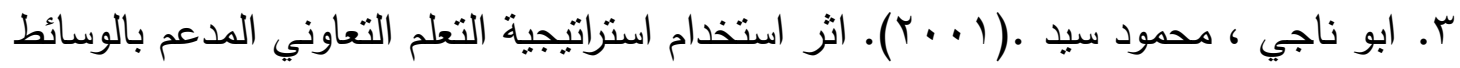
الفعالة للكومبيوتر في تدريس العلوم وتتمية الاتجاهات العلمية،مجلة كلية التربية، العدد V V.

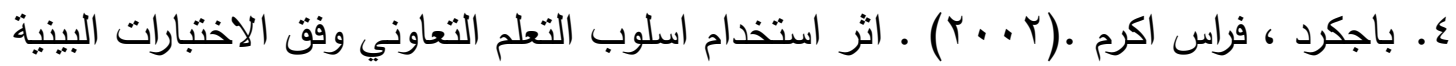


الرياضية ، جامعة صلاح الدين.

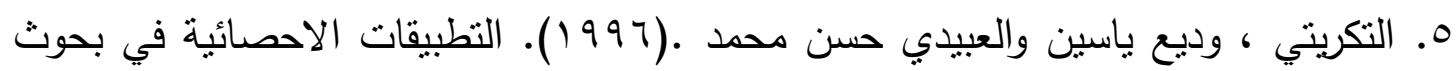
التربية الرياضية ، دار الكتاب للطباعة والنشر ، جامعة الموصل.

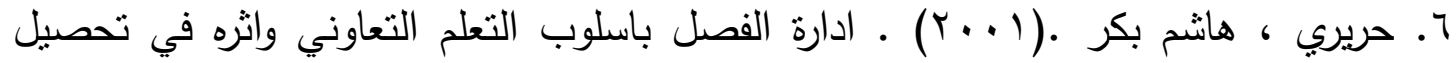
الطلاب الدراسي (انت).

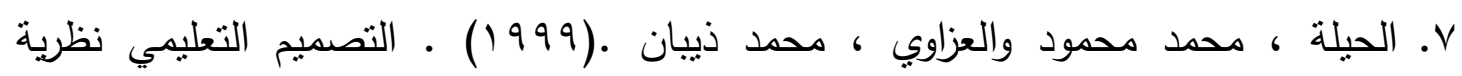



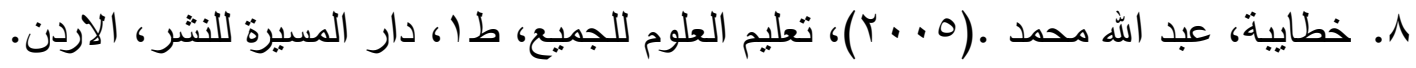

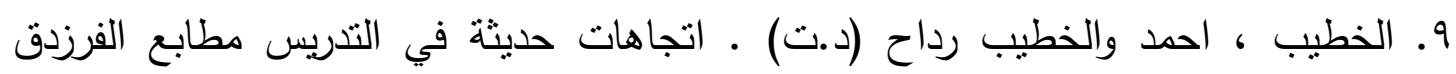
التجارية ، عمان ، الاردن. - مان.

• (.السامرائي عباس والسامرائي عبد الكريم .(199 (1). كفايات تدريسية في طرائق تدريس التربية الرياضية ، دار الحكمة ، جامعة البصرة. ا (الثافعي ، ابراهيم محمد و آخرون .(1997 (1). المنهج المدرسي من منظور جديد ، مكتبة

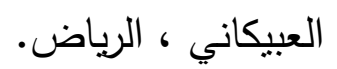

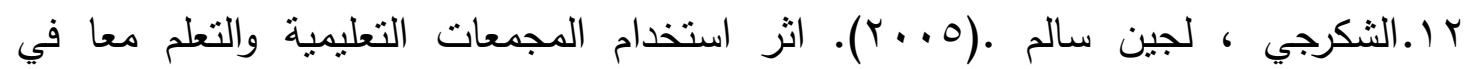
التحصيل والاتجاهات نحو مادة الجغرافية، اطروحة دكتوراه غير منشورة ، جامعة الموصل ، 




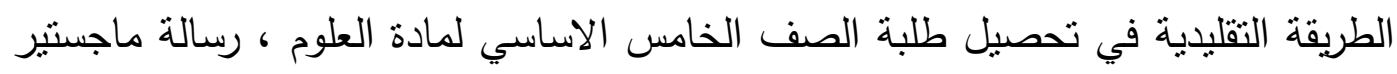
غير منشورة ، جامعة مؤتة ، الاردن.





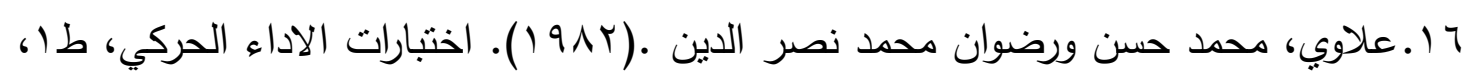
دار الفكر العربي ، القاهرة.

V V.المنسي ، حسن عمر .(1990). اثر التعلم التعاوني في التحصيل لدى طلبة المرحلة



$$
\text { التربية ، السودان. }
$$

18. Maning , N. (1991) The what way and how for cooperative learning, the social studies, Vol. (82), No. 3. 


\section{نموذج لوحدة تعليمية باستخدام إستراتيجية تدريس الأقران}

الوحدة التعليمية الثانية

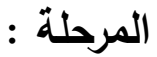

الزمن : 9 دقيقة

اليوم : - الي

الهذف التعليمي : الاحرجة بوجه القدم الامامي و

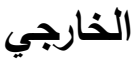

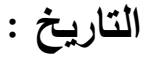

الهذف التربوي : التأكيد على العمل في مجموعات

تعاونية

\begin{tabular}{|c|c|c|}
\hline التنظيم & 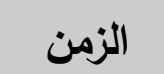 & 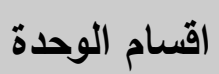 \\
\hline & 10 & الاعدادي \\
\hline اخذ الغياب وتعيئة الادوات & 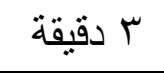 &  \\
\hline \multirow[t]{2}{*}{ تهيئة عامة وخاصة لجميع اعضاء الجسم } & r r ا دقيقة & الاحماء \\
\hline & 年 &  \\
\hline شرح مهارة الدحرجة مع عرض نموذج من قبل المدرس & 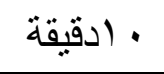 & 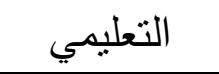 \\
\hline  & 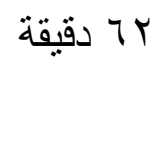 & النطبيقي \\
\hline الدحرجة المستقيمة بوجه القدم الامامي (· م) ذهابا وايابا & م دقيقة & تمرين (1) \\
\hline  & م دقيقة & تمرين (Y) \\
\hline دحرجة زكزالك (0 شواخص) ذهابا فقط & م دقيقة & تمرين (r) \\
\hline دحرجة زكزالك (v شواخص) ذهابا وايابا & م دقيقة & تمرين (ع) \\
\hline ممارسة لعب مع التأكيد على المهارة المعطاة &  & لعب \\
\hline تمارين تهيئة ثم الانصراف. &  & 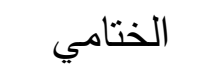 \\
\hline
\end{tabular}

